\title{
Application of Fully Coupled Activated Sludge Model No. 3 in Municipal Sewage Treatment Plant
}

\author{
Zhifei Ding ${ }^{1}$, Juqing Lou ${ }^{2, *}$ and Minghao Zhou ${ }^{1}$ \\ ${ }^{1}$ Hangzhou Foreign Languages School, Hangzhou, China \\ ${ }^{2}$ Zhejiang Gongshang University, Hangzhou, China \\ ${ }^{*}$ Corresponding author
}

\begin{abstract}
At present, operating most wastewater treatment plants (WWTP) in China typically relies on experiences of managers, that is, fuzzy control. However, sewage water quality fluctuates and is frequently unstable given the intensified modernization. Fuzzy control cannot satisfy the requirements of microbial growth during sewage treatment. Thus, a mathematical model is required to realize the intelligent control of sewage treatment plant, thereby providing real-time and accurate environmental conditions and process conditions suitable for microbial growth. Simulation and control based on the model is an effective method for achieving this goal. The mechanism model can simulate a biological reaction process in complex biochemical systems, predict the water quality of sewage treatment plant, and analyze process operation. This model also aims to guide the operation and management of sewage plants, thereby attaining the optimal design of WWTPs and operation of optimization.
\end{abstract}

Fully coupled activated sludge model no. 3 (FCASM3) is a microscopic mechanism model for removing nutrients in an activated sludge system. FCASM3 can simulate the quality of effluent water well; thus, it can be used in upgrading and reconstruction.

An FCASM3 model was used to simulate $A+A^{2} / O$ process in Hangzhou Western WWTP in this study. Our scope includes monitoring the quality of influent and analyzing a model ingredient and predicting water quality of effluent by using FCASM3. The influents and effluents of the WWTP were used to reexamine the results for FCASM3, thereby showing that the results applied to Hangzhou Western WWTP. Orthogonal experiments were conducted on the basis of dissolved oxygen and activated sludge and mixed liquid return ratios. The FCASM3 model was used to simulate the optimal process parameters. Simulation results showed that the optimal operating parameters of Hangzhou Western WWTP are a sludge return rate of $75 \%$, mixed liquor returning flow rate of $100 \%$, and oxygen transmit velocity $K_{\mathrm{L} a}$ is $50 \mathrm{~d}^{-1}$.

Keywords-Fully Coupled Activated Sludge Model No.3 (FCASM3), simulation, municipal sewage treatment plant

\section{INTRODUCTION}

The industrialization and urbanization in China and the social economy have progressed rapidly in recent years. However, pollution is worsening, and sewage treatment is becoming an essential part of economic development and water resource protection. China is a country with different environmental conditions, and water quality and yield in wastewater treatment plants (WWTP) are changing dynamically. Therefore, environmental conditions and water quality significantly affect the treatment of WWTPs. Furthermore, enterprises widespread theft and drainage, the fluctuation range of sewage water quality and amount, especially the severe impact of toxic and hazardous substances on urban sewage treatment plants, given the pollution from urban sewage source, thereby leading to the stable and standard of WWTP effluent quality. Sewage plants lack corresponding scientific management tools. Currently, the operation and management of urban sewage treatment plants are mainly based on manual operation experience, and the process adjustment constantly results in failure. Thus, optimizing and adjusting environmental and process conditions in the early stage of abnormal situation is infeasible and meeting the standards is difficult, the treatment system can even be paralyzed[1].

At present, urban sewage treatment plants have achieved large-scale automation control; these systems are controlled by a central system and can monitor the fluctuation of water quality in real time. However, the automation has not realized the adaptive and intelligent feedback control in which the process parameters are based on dynamic changes in water quality and quantity. The central control system cannot analyze the data from monitor results or judge the condition of the operation, thereby possibly leading to problems of being delayed and efficient control being unrealized, thus affecting the stable operation of WWTPs. The real-world result has failed to enact the actual automation operation and management. Therefore, in research on urban sewage treatment, automating sewage treatment plant and constructing an intelligent sewage treatment plant will be beneficial to improving the efficiency of the optimization process of sewage treatment plant; additional effects shorten the design cycle, reduce the cost of wastewater treatment process parameter optimization control test, and generate a well-developed optimization scheme of the process control of urban sewage treatment plant[2].

A multiparameter dynamic comprehensive control model of energy-saving and cost-reduction for actual wastewater consumption in China can be established by studying the removal mechanism of pollutants for municipal WWTPs. The model can be applied to guide the process construction of urban sewage treatment plant. In further controlling the sewage treatment plant through negative feedback optimization, the 
experience can be used to analyze quantitative analysis. The scheme of process operating parameters and optimized operation can be determined by applying online sensors and programmable logic controllers. An intelligent sewage treatment plant is established. It is a new technology that reduces the energy consumption of the process and improves the utilization rate of energy while ensuring water quality, which is suitable for energy-saving and cost-reduction[3].

In recent years, the mechanism of activated sludge treatment for sewage treatment is increasingly thorough with the development of technology and research; this mechanism is in the form of activated sludge models, such as the activated sludge model series of the International Water Association, the Canada BioWin model, and the biological nutrient removal series model of Spain[4]. The complex composition of Chinese hybrid sewages, such as heavy metals and other poisonous and harmful substances, significantly affects the biochemical process of activated sludge systems. The International Water Association series model only applies to a simulated sewage treatment process in which the domestic sewage represents 95\% and above. Therefore, these models do not apply to Chinese sewage treatment plants[5]. Thus, Sun Peide of Zhejiang Gongshang University independently developed a model of fully coupled activated sludge series (FCASMs) on the basis of MATLAB and the characteristics of a hybrid wastewater[6,7,8]. The model based on an in-depth analysis of a reaction mechanism of biologically activated sludge systems sets up a sub-microscopic mechanism model for biological removal of nutrients in an activated sludge system, namely, fully coupled activated sludge model no. 3 (FCASM3)[9]. FCASM3 subdivides microorganisms into eight groups of bacteria and considers the interaction among microbes in the system, which increases the component and sub-process to 31 and 72 , respectively[10,11]. Simultaneously, FCASM3 introduced an intermediate product of nitrite in the nitrification-denitrification process, and the simulation of a two-step nitrification-denitrification process was attained[12]. FCASM3 also considers the bioprocesses of polysaccharides[13]. This series model can simulate water quality accurately and has been used in upgrading and reconstructing actual sewage treatment plants.

In this study, the FCASM3 model was applied to the numerical simulation of Hangzhou Western WWTP, and the optimal operating parameters of the plant was determined through a simulation.

\section{Simulation Process And Methods}

\section{A. Process of Hangzhou Western WWTP}

The Hangzhou Western WWTP is located in Tanghe Village, Sandun Town, West Lake District, Hangzhou City, near the Yuhang Tang River. The Western WWTP is mainly responsible for the area of Jiangcun Village, block of the north of Wenyuan Road and west of Zijingang, west of Zijingang Campus Zhejiang University, Xixi Wetland Reserve, West Lake District prospect development block (Shuangqiao Area), and residential area of the north of Sandun Town and Shangsi areas. The Western WWTP uses the improved A/A/O secondary sewage and micro-flocculation filtration depth treatment processes. The sewage treatment process is illustrated in Figure 1. The first stage of water quality satisfies the requirements of grade A (CODcr $\leq 40 \mathrm{mg} / \mathrm{l})$ of the pollutant discharge standards for urban sewage treatment plants (GB18918-2002)[14]. The water quality will be compliant with the "AA standard" after implementing the second phase of the project. The technical parameters of the Western WWTP are listed in Table 1 . The annual average water quality in the first half of 2017 is summarized in Table 2 .

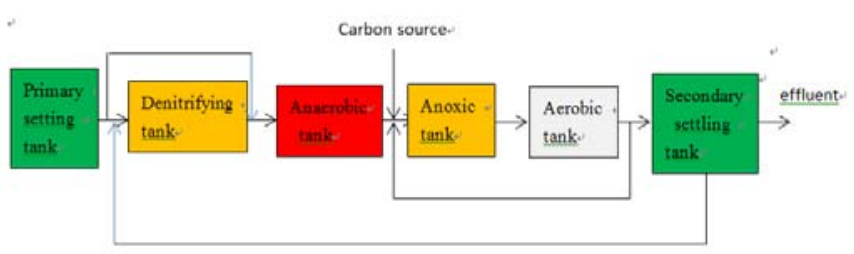

FIGURE I. FLOWCHART OF THE WESTERN WWTP PROCESS

TABLE I. TECHNICAL PARAMETERS OF THE WESTERN WWTP

\begin{tabular}{ll}
\hline Projects & Value \\
\hline Mean value of actual water inlet flow Q & $34000 \mathrm{~m}^{3} \cdot \mathrm{d}^{-1}$ \\
Return current ratio of the mixed liquid $\mathrm{r}$ & $150 \%-200 \%$ \\
Sludge reflux ratio R & $100 \%$ \\
Denitrification pool volume V1 & $1600 \mathrm{~m}^{3}$ \\
Anaerobic pool volume V2 & $1600 \mathrm{~m}^{3}$ \\
Anoxic pool volume V3 & $4800 \mathrm{~m}^{3}$ \\
Aerobic pool volume V4 & $11900 \mathrm{~m}^{3}$ \\
\hline
\end{tabular}

TABLE II. ANNUAL MEAN OF THE WATER QUALITY IN 2017

\begin{tabular}{cccc}
\hline $\mathbf{C O D} /\left(\mathbf{m g} \cdot \mathbf{L}^{-1}\right)$ & $\mathbf{N H}{ }^{+}-\mathbf{N} /\left(\mathbf{m g} \cdot \mathbf{L}^{-1}\right)$ & $\mathbf{T N} /\left(\mathbf{m g} \cdot \mathbf{L}^{-1}\right)$ & $\mathbf{T P} /\left(\mathbf{m g} \cdot \mathbf{L}^{-1}\right)$ \\
\hline 174.5 & 25.8 & 30.67 & 2.84 \\
\hline
\end{tabular}

\section{B. Simulation and Method}

(1) In accordance with the FCASM3 model, we determined the parameters of the model and built the model of the Western WWTP by determining the west sewage treatment plant influent components combined with the operating conditions and water quality requirements of the Hangzhou Western WWTP $\mathrm{A}+\mathrm{A}^{2} / \mathrm{O}$ process .

(2) We used the actual operation data of the plant in the first half of 2017 and checked the data to verify the model.

(3) The main process parameters of the plant were numerically simulated by using the model. For the $A+A^{2} / O$ process, three process parameters, namely, dissolved oxygen, sludge reflux ratio, and mixture reflux ratio, significantly affect the pollutant treatment effect of the system. The lack of dissolved oxygen in an aerobic tank will inhibit the activity of nitrifying bacteria and the growth of heterotroph bacteria, thereby affecting the removal of organic matter, nitrification reaction, and phosphorus absorption process. The sludge recirculation ratio determines the sludge age of the activated sludge in the system and significantly affects the phosphorus removal efficiency of the polyP bacteria. The mixture reflux 
ratio influences the anoxic denitrification process. If the mixture reflux ratio is small, which will lead to a minimal flow of nitrification, then this ratio will not only affect the growth of denitrifying bacteria but also directly affect the removal efficiency of $\mathrm{TN}$ in the final effluent. If the reflux ratio of dissolved oxygen in the aerobic tank is significantly large to carry to an anoxic tank; anoxic conditions will affect the anoxic denitrifying bacteria, thereby inhibiting activity. This process will reduce the concentration of organic carbon in the anoxic tank and is detrimental to the denitrification of the denitrifying bacteria. Thus, an optimal combination of process parameters occurs for a particular process of operation. Owing the synergistic effect among various factors, this study uses the orthogonal test to determine the best operating conditions of the Hangzhou Western WWTP. Orthogonal test protocols were listed following the orthogonal test table of four factors and three levels, as displayed in Table 3.

TABLE III. ORTHOGONAL TABLE FOR OPERATION PARAMETERS

\begin{tabular}{llll}
\hline Test group & $\begin{array}{l}\text { oxygen transfer } \\
\text { rate } \\
\boldsymbol{K}_{\mathbf{L} \boldsymbol{a}} / \mathbf{d}^{\mathbf{- 1}}\end{array}$ & $\begin{array}{l}\text { mixture } \\
\text { ratio } \\
\mathbf{r} / \%\end{array}$ & $\begin{array}{l}\text { reflux } \\
\text { sludge reflux } \\
\text { ratio R/\% }\end{array}$ \\
\hline 1 & 25 & 100 & 50 \\
2 & 25 & 200 & 100 \\
3 & 25 & 300 & 75 \\
4 & 50 & 100 & 75 \\
5 & 50 & 200 & 50 \\
6 & 50 & 300 & 100 \\
7 & 100 & 100 & 100 \\
8 & 100 & 200 & 75 \\
9 & 100 & 300 & 50 \\
\hline
\end{tabular}

III. RESULTS AND DISCUSSION

\section{A. Establishment of the Biological Coupling Model of FCASM3 Active Sludge System}

The basic assumption of improving the biological field model on the basis of the combination of the operating conditions and water quality requirements of Hangzhou Western WWTP $\mathrm{A}+\mathrm{A}^{2} / \mathrm{O}$ process can establish a sound FCASM3 system. Simultaneously, in the operating conditions of the $\mathrm{A}+\mathrm{A}^{2} / \mathrm{O}$ process, the water dispersion process of pollutant transformation and microbial activity affects the distribution. The numerical model is combined with the flow and biological flow field on the biochemical reaction of the Western WWTP numerical simulation.

1) Determination of the conventional sewage treatment water quality index: Sampling was conducted in each biochemical pool of the Western WWTP in June 2017. We measured the water quality index of the biochemical pool. The conventional water quality indicators were chemical oxygen demand (COD), nitrite nitrogen $\left(\mathrm{NO}_{2}{ }^{-}-\mathrm{N}\right)$, nitrate nitrogen $\left(\mathrm{NO}_{3}{ }^{-} \mathrm{N}\right)$, ammonia nitrogen $\left(\mathrm{NH}_{4}{ }^{+}-\mathrm{N}\right)$, and phosphate $\left(\mathrm{PO}_{4}{ }^{3-}-\right.$ $\mathrm{P})$. The concentrations are demonstrated in Figure 2.

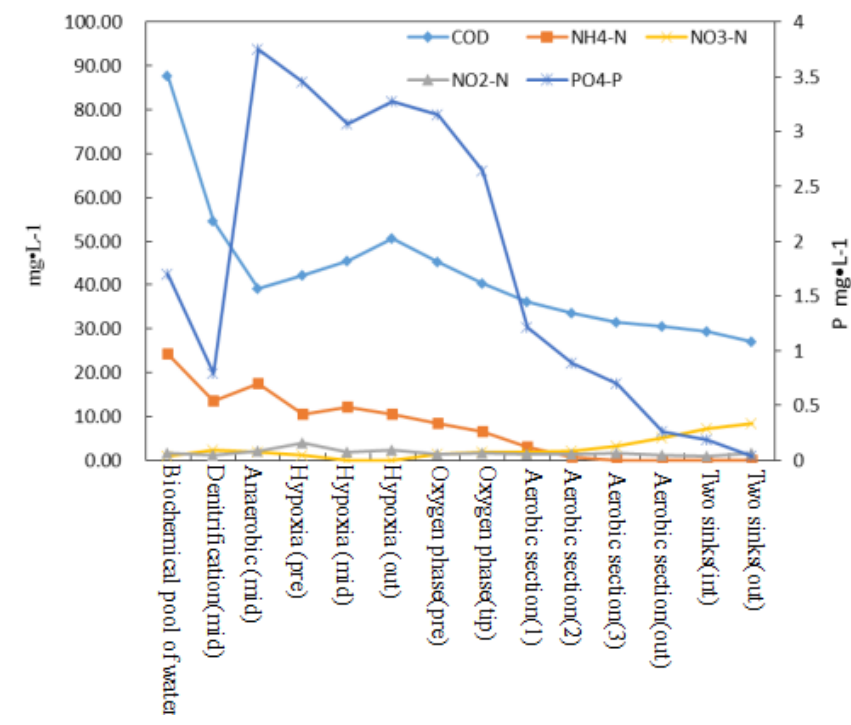

FIGURE II. WWTP WATER QUALITY INDEX OF ROUTINE MEASUREMENT DATA

2) Typical model of water quality component analysis: The $\mathrm{A}+\mathrm{A}^{2} / \mathrm{O}$ model was established to be verified by the historical data in stable operation of the WWTP in the first half of 2017. The water inlet of the water samples was measured to confirm the water quality components and parameters of the model. The experiment was conducted through aerobic batch respirometric method by drawing the oxygen uptake rate curve determination of influent Ss and Xs. The water quality component analysis is depicted in Figure 3

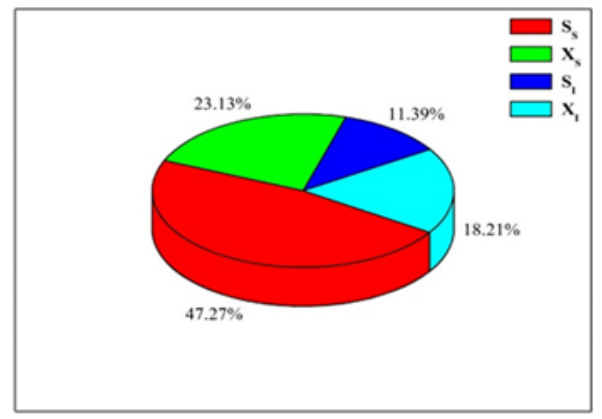

FIGURE III. TYPICAL WATER QUALITY ANALYSIS

\section{B. Model Checking}

The historical data on $\mathrm{COD}, \mathrm{NH}_{4}{ }^{+}-\mathrm{N}, \mathrm{NO}_{3}{ }^{-}-\mathrm{N}$, and $\mathrm{PO}_{4}{ }^{3-}-\mathrm{P}$ determination results verify the FCASM3 model by studying the Western WWTP in the first half of 2017. The checking model simulation value is compared with the measured values. Reliability and accuracy evaluations are conducted. The FCASM3 model and its simulation of aerobic tank effluent $\mathrm{COD}, \mathrm{NH}_{4}{ }^{+}-\mathrm{N}, \mathrm{NO}_{3}{ }^{-}-\mathrm{N}$ and $\mathrm{PO}_{4}{ }^{3-}-\mathrm{P}$ concentrations were compared with the measured values, as displayed in Figure 4.

Figure 4 illustrates that the simulation of a water change trend of $\mathrm{COD}$ and $\mathrm{PO}_{4}{ }^{3-}-\mathrm{P}$. The actual water change trend is consistent, and the actual trend is relatively stable. The simulations of COD, $\mathrm{NH}_{4}{ }^{+}-\mathrm{N}$, and $\mathrm{PO}_{4}{ }^{3-}$-P have attained a high 
stability, and the simulated value of an average relative error with the measured values is small. The mechanism of the
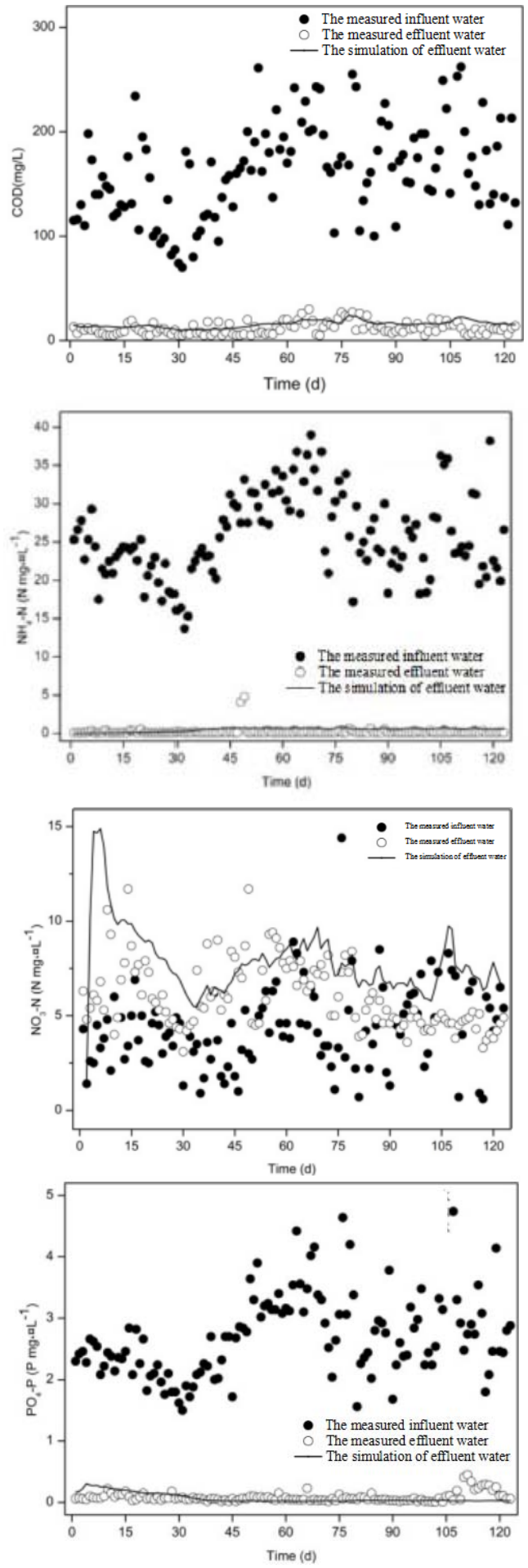

FIGURE IV. COMPARISON CHART OF THE AEROBIC TANK EFFLUENT COD, $\mathrm{NH}_{4}{ }^{+}-\mathrm{N}, \mathrm{NO}_{3}{ }^{-}-\mathrm{N}, \mathrm{AND} \mathrm{PO}_{4}{ }^{3-}-\mathrm{P}$ FCASM 3 SIMULATION AND MEASURED VALUES

FCASM3 model and the transformation of ammonia nitrogen and phosphate removal process description is accurate in removing organic compounds. The simulation results of the $\mathrm{NO}_{3}{ }^{-}-\mathrm{N}$ system in biochemistry reaction is slightly poor, that is, slightly higher than the real value, but is an improved simulation of the variation trend of nitrate in an aerobic tank potential. This result may be due to the default in the model system in the aerobic pool of dissolved oxygen distribution, whereas the actual aerobic pool is divided into three lattices using the plug flow. This situation results in the distribution of dissolved oxygen in the system being not very uniform. A conversion of nitrate mainly occurs given the nitrifying and denitrifying bacteria. The low distribution of dissolved oxygen in the aerobic tank and sludge reflux is uneven, thereby resulting in low nitrate concentration and measured and simulated values of a slight deviation. In general, FCASM3 on the WWTP $\mathrm{A}+\mathrm{A}^{2} / \mathrm{O}$ process can effectively simulate the transformation of the material in the system, and the simulation results are convincing.

\section{Numerical Simulation of the WWTPs under Optimal Operating Conditions}

Under the dynamic water inflow and water quality conditions, we use the operation data of the WWTP during the first half of 2017 to simulate the $\mathrm{COD}, \mathrm{NH}_{4}{ }^{+}-\mathrm{N}, \mathrm{NO}_{3}{ }^{-}-\mathrm{N}$, and $\mathrm{PO}_{4}{ }^{3-}-\mathrm{p}$ of the $\mathrm{A}+\mathrm{A}^{2} / \mathrm{O}$ systems with different process combinations on the basis of the calibrated SBR model. The simulation results are presented in Figure 5.

The comparison of the simulations of the COD indicates that the value is higher in Test 1 than in other groups (Figure $5 a)$.

Figures $5 \mathrm{~b}, 5 \mathrm{c}$, and $5 \mathrm{~d}$ illustrate that the simulation result of effluent $\mathrm{NH}_{4}^{+}-\mathrm{N}$ is higher in Tests $1-3$ than in the other groups, especially Tests 2 and 3. The values are obviously lower in Tests 1-3 than in the other groups by analyzing the simulation of $\mathrm{NO}_{3}{ }^{-}-\mathrm{N}$. The simulations in Tests 2 and 3 are slightly higher in $\mathrm{NO}^{2-}-\mathrm{N}$ than in the other groups. The study indicates that DO plays an important role in denitrification. Under a high dissolved oxygen concentration, nitrogen removal mainly concerns the entire process of nitrification. A short-cut nitrification has been gradually enhanced because the process of nitrogen removal is dominated by short-cut nitrification (Tests 2 and 3 ) under the low dissolved oxygen concentration because the dissolved oxygen concentration decreases when the concentration drops to a certain level.

Figure 5e depicts that the simulation result of $\mathrm{PO}_{4}{ }^{3-}-\mathrm{P}$ is higher in Tests 6-8 than in the other groups, and the dissolved oxygen concentration in Tests $6-8$ are also at a high level. In Aerobic section 3 , the average dissolved oxygen concentration has reached $6.2 \mathrm{mg} . \mathrm{L}^{-1}$, which indicates that a high dissolved oxygen concentration is not conducive to phosphate removal. However, the simulation of $\mathrm{PO}_{4}^{3-}-\mathrm{P}$ in Test 9 under a high dissolved oxygen concentration is low, thereby indicating that the increase in the reflux ratio of mixed liquid and the decrease in the sludge reflux ratio can enhance the effect of phosphate removal.

In Figure 5f, the effects of SS removal in each group are similar when simulating SS. The values are slightly higher in Tests 7-9 than in the other groups because part of the activated sludge is oxidated under the high dissolved oxygen 
concentration in the aeration tank, thereby resulting in a high effluent SS.
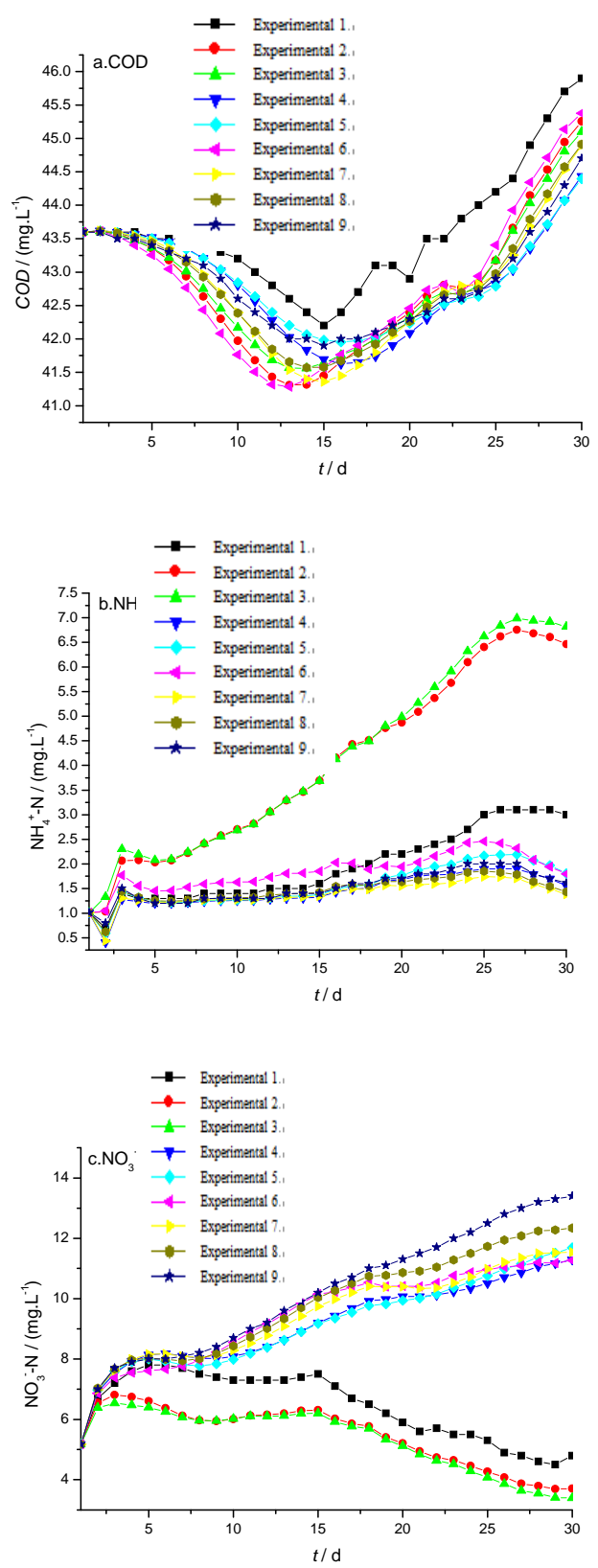
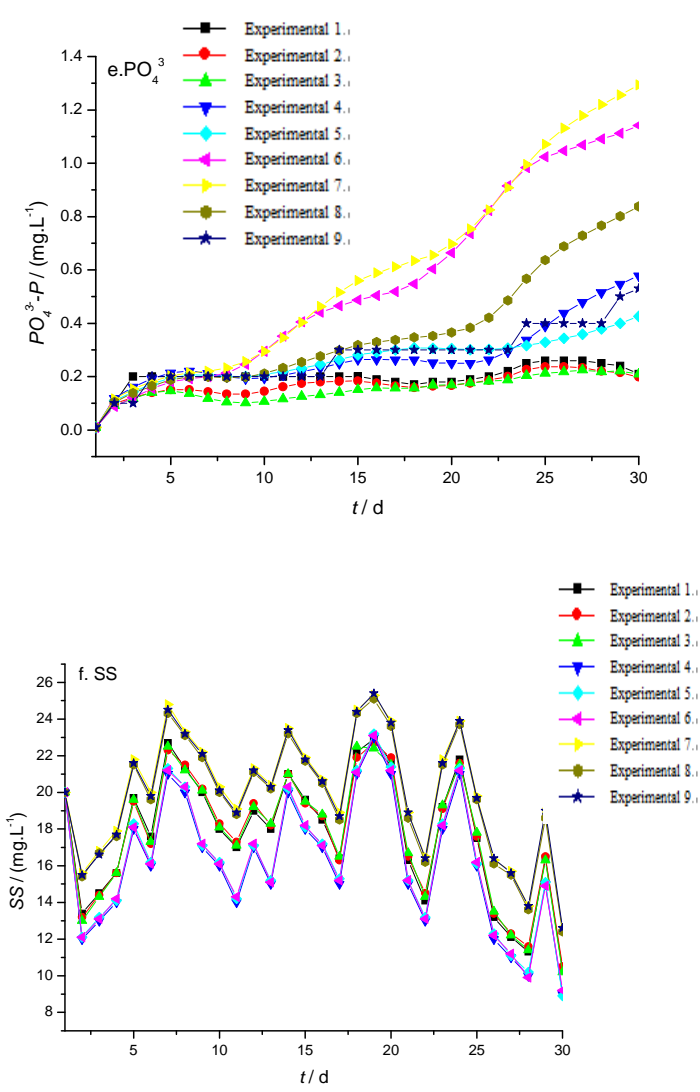

FIGURE V. RESULTS OF THE ORTHOGONAL SIMULATION TEST

The reflux ratio of the mixed liquid is $100 \%$, the sludge reflux ratio is 0.75 , and the oxygen transfer rate is $50 \mathrm{~d}^{-1}$ in the $\mathrm{A}+\mathrm{A}^{2} / \mathrm{O}$ system of Chengxi WWTP, as presented in Scheme 4 of the simulation test. The system reflects the optimal removal effect of $\mathrm{C}, \mathrm{N}, \mathrm{p}$, and SS under this condition, thereby adhering to emission requirements and saving on running costs.

\section{CONCLUSIONS}

(1) The results obtained by the SS accounted for $66 \%$, XS for $96 \%$, XI for $15.85 \%$, and SI for $10.56 \%$ through the model component analysis of the influent of Chengxi WWTP. 
(2) The operation data of Chengxi WWTP during the first half of 2017 were applied to calibrate the FCASM3 model, and the result showed that the model can be used for the operation of the WWTP. Furthermore, the model could be applied to the operation guidance of the $\mathrm{A}^{2} / \mathrm{O}$ process of other similar sewage treatment plants.

(3) The results of the orthogonal test from the FCASM3 model showed that the optimal operating parameters of Hangzhou Chengxi WWTP are as follows: sludge reflux ratio is $75 \%$, mixed liquid reflux ratio is $100 \%$, and oxygen transmission rate $K_{\mathrm{L} a}$ is $50 \mathrm{~d}^{-1}$. The WWTP can maintain the optimal pollutant removal effect under this condition.

\section{ACKNOWLEDGMENT}

This study was funded by by the key project of science and technology of Zhejiang Province, China (No.2014C03002) and the central government's specially supported funding for the development of local colleges and Universities (No.S1701).

\section{REFERENCES}

[1] R. Zhao. Dynamic monitoring - simulation - control integrated intelligent SBR test system development and operation [D]. Hangzhou: Zhejiang Gongshang University, 2016 (in chinese).

[2] X.F. Zhou, G.W. Gu, J.Y. Liu, Y.P. Guo. Mathematical Modeling of Biological Process in Wastewater Treatment Plant [J]. Journal of Tongji University (natural science), 2004, (6): 745-748 (in chinese).

[3] H.C. Shi, H.F. Yan, H. Liu, Y.X. Wang, X.Y. Ke. Application of the Software for Operation Simulation and Prediction in Municipal Wastewater Treatment Plant [J]. China Water Wastewater, 2001, 17(10): 61-63 (in chinese).

[4] Q. Yang, Z.Q. Liu, S.Y. Gan. Application of ASM3 in Reconstruction of Municipal Wastewater Treatment Plant [J]. China Water Wastewater, 2002, (12): 68-70 (in chinese).

[5] D.J. Zhang, P.L. Lu, C.M. Yan, T.R. Long. Application of ASM No.2 to the study of upgrading WWTP for biological nitrogen and phosphorus removals [J]. Acta Scientiae Circumstantiae, 2003, 23(3): 332-337 (in chinese).

[6] P.D. Sun, Y.Q. Song. 2006. Study on full coupled activated sludge model (FCASM) based on coupling interaction mechanism of microorganisms [J]. Acta Scien tiae Circumstantiae, 2006, 26(9): 1559 1567 (in chinese).

[7] P.D. Sun, R.Y. Wang. Biological-hydraulic coupled modelo factivated sludge wastewater treatment plants and modelvalidation [J]. Acta Scientiae Circumstantiae, 2007, 27(9): 1557 -1566 (in chinese).

[8] P.D. Sun, R.Y. Wang, Z.G. Fang. Fully coupled activated sludge model (FCASM): Model development [J]. Bioresour Technol, 2009, (100): 4632-4641.

[9] P.D. Sun, R.Y. Wang. Fully coupled activated sludge model (FCASM3) Part I : Mechanism and expression [J]. Acta Scientiae Circumstantiae, 2008, 27 (12): 2404-2419 (in chinese).

[10] R.Y. Wang, P.D. Sun, Y.Q. Song. Fully coupled activated sludge model (FCASM3) Part II : Modelvalidation [J]. Acta Scientiae Circumstantiae, 2008, 28 (12): 2420-2429 (in chinese).

[11] Y.B. Chen, P.D. Sun, W.G. Ma, G.Q. Lou. Numerical stimulation of the optimum operational condition for nitrogen and phosphorus removal in tubifex-microbe symbiotic system [J]. Acta Scientiae Circumstantiae, 2012, 32 (11): 2770-2780 (in chinese).

[12] P. Sun, R. Wang, Z. Fang. Fully coupled activated sludge model (FCASM): model development [J]. Bioresource Technology, 2009, (100): 4632-4641.

[13] J.N. Bing, Q.Y. Han. Anapproach for modeling two-step denitrification in activated sludge systems [J]. Chemical Engineering Science, 2008, (63): 1449-1459.
[14] SBTS. Discharge standard of pollutants for municipal wastewater treatment plant, GB18918-2002, China. 